\title{
Individual differences in McCollough effects: A study of twins
}

\author{
DIANE SKOWBO and LINDA MICHAUD \\ Colby College, Waterville, Maine
}

\begin{abstract}
In an investigation of individual differences in McCollough effects (MEs), we induced MEs in 15 sets of twins. Subjects matched both the subjective ME colors and actual colors that resembled MEs. We found greater intersubject variability among matches to MEs than among matches to physical hues. Intraclass correlations between twins' matches were statistically significant and were similar in magnitude regardless of the source of the perceived color. Our results support the hypothesis that individual differences in MEs have a systematic component related to subjects' biological characteristics.
\end{abstract}

Color aftereffects that are contingent upon the spatial characteristics of lined patterns were first reported by McCollough (1965). In twenty years of investigation, a substantial amount of information has been gathered on stimulus characteristics that affect the acquisition and decay of McCollough effects (MEs) (see, e.g, reviews by Harris, 1980; Shute, 1979; Skowbo, Timney, Gentry, \& Morant, 1975; Stromeyer, 1978). MEs may also be influenced from within the body by the manipulation of drugs (Amure, 1978; Shute, 1979) and sleep cycles (Lund \& MacKay, 1983). In addition, interindividual differences in MEs are frequently mentioned in the literature (see, e.g., Riggs, White, \& Eimas, 1974; Skowbo, Garrity, \& Michaud, 1985; White, 1977), but, to our knowledge, only one study has systematically explored the influence of a subject characteristic. This investigation, conducted by Bologna, May, and Kunen (1984), found that ME magnitudes were greater in children than in college students.

Interindividual differences have received somewhat more attention in the literature on other types of aftereffects, such as kinesthetic aftereffects (e.g., Cavonius, Hilz, \& Chapman, 1974; Weintraub, Green, \& Herzog, 1973), movement aftereffects (e.g., Harris, 1983; Reilly, 1970), and afterimages (e.g., Kline \& Nestor, 1977; McGuinnes \& Lewis, 1976). In addition, several studies have reported data on the similarity of twins' reactions to various illusions, including the Ponzo illusion (Matheny, 1971), the double trapezium illusion (Matheny, 1973), and the escalator movement illusion (Fraser \& Wilcox, 1979). Coren and Porac (1979) also found familial resemblances in subjects' experiences of the Müller-Lyer and Ebbinghaus illusions.

This research was supported by funding from Colby College. Requests for reprints should be sent to D. Skowbo, Psychology Department, Colby College, Waterville, ME 04901 . We are grateful for the participation of $M$. and $M$. Alexander, $C$. and F. Dodge, $R$. and $R$. Dutil, $R$, and $S$. Goldenthal, J. and J. Gush, R. and R. Lawrence, J. and J. Levesque, G. and S. MacKnight, J. and J. McLeod, $H$. and $H$. Mitchell, $H$. and H. Moon, J. and J. Moore, J. and J. Turmelle, J. and J. Whittemore, and $\mathbf{M}$. and M. Witham.
In the present study, we extend this approach to MEs. Our purpose is not to establish heritability of MEs, but to investigate individual differences in MEs by (1) comparing variability within twin pairs to variability among all subjects, and (2) comparing twins' MEs with their perceptions of physically generated colors.

\section{METHOD}

\section{Subjects}

Subjects were recruited via newspaper ads and notices sent to local school systems. Twenty sets of twins responded and were brought to the laboratory for initial screening: They were given tests for resolution and stereoscopic acuity, and they completed the Farnsworth-Munsell 100-Hue Test. On the basis of the test results, 5 sets of twins were excluded from further study. ${ }^{1}$ Among the individuals in the 15 remaining sets, error scores on the FarnsworthMunsell Test were in the range of average color discriminating ability. One set of twins had Snellen acuity of 20/30; the rest had corrected or uncorrected acuities of $20 / 20$ or $20 / 15$. None showed any evidence of hyperopia, and all had normal stereoacuity. They ranged in age from 10 to 15 years. All sets were same-sexed, with 7 female sets and 8 male sets. Tests for zygosity were not carried out; 8 sets (of which 5 were female) were believed by their parents to be identical twins.

\section{Apparatus and Stimuli}

Subjects sat facing a circular piece of acrylic rear-projection material mounted on a black background. The stimuli that were projected onto this surface were all $21^{\circ}$ in diameter.

The stimuli used to induce MEs were prepared from 1.75cycles/deg gratings and Kodak Wratten filters (No. 53 or No. 32). These magenta and green grating patterns had space-averaged luminances of, respectively, $16 \mathrm{~cd} / \mathrm{m}^{2}$ and $17 \mathrm{~cd} / \mathrm{m}^{2}$.

The stimulus used for testing MEs was an achromatic grating pattern with lines oriented vertically on its top and horizontally on the bottom. In its center was an unlined circular area $7^{\circ}$ in diameter. Light falling on this central spot could be varied in chromaticity by subjects' adjusting a knob as they tried to match MEs seen on the surrounding lined area. The source of this light was a projection colorimeter that mixed light transmitted by two Kodak Wratten color-compensating filters (Nos. CC30M and CC50G). In C.I.E. color space, all mixtures of these two filters fall on a straight line connecting the two points that represent the loci of the filter primaries-in our system, their coordinates are $x=.407, y=.454$ and $x=.421, y=.350$. The space-averaged luminance of the test 
grating was $.52 \mathrm{~cd} / \mathrm{m}^{2}$ (see, e.g., White, 1976, for a discussion of test-pattern luminance as a parameter in the assessment of MEs) and the luminance of the homogeneous matching spot was $1.2 \mathrm{~cd} / \mathrm{m}^{2}$.

Two unlined bicolor stimuli (BCS), pinkish on top and greenish on the bottom, were prepared from Kodak Wratten colorcompensating filters. One stimulus (prepared with filters CC10G $+\mathrm{CC} 05 \mathrm{M}$ ) was slightly less saturated than the other (prepared with CC20G + CC10M). The less saturated bicolor stimulus (BCS1) had a luminance of $.67 \mathrm{~cd} / \mathrm{m}^{2}$; the more saturated bicolor stimulus (BCS2) had a luminance of $.73 \mathrm{~cd} / \mathrm{m}^{2}$. Like the test slide, each stimulus had an empty central area on which the matching spot was projected. The stimuli were used to give subjects practice at matching weakly saturated hues and also to provide an index of subjects' perceptions of physically chromatic stimuli similar to those seen as MEs. A homogeneous achromatic stimulus with a luminance of $1.2 \mathrm{~cd} / \mathrm{m}^{2}$ was used for light-adaptation purposes.

\section{Procedure}

Members of twin sets came to the laboratory together but were tested separately, one after the other. They began each session with $1 \mathrm{~min}$ of light adaptation, then were shown the test slide and asked to comment on its appearance. Next, they matched the appearance of the two halves of one BCS in ABBA sequence; this was repeated for the other BCS.

$M E$ induction followed: Subjects watched the two induction stimuli alternating every $10 \mathrm{sec}$ for $5 \mathrm{~min}$. At the end of the induction period, subjects viewed the light-adaptation slide for $1 \mathrm{~min}$, then the test pattern reappeared and subjects matched the appearance, again in ABBA sequence, of the vertical and horizontal portions.

Subjects participated in four sessions. These were separated by intervals that ranged from 8 to 33 days, with a mean of 18 days. Color/orientation combinations in the induction stimuli were reversed in successive sessions.

\section{RESULTS}

Orientation-specific colors were reported on the test slide at the beginning of 11 of the 120 sessions. $^{2}$

Subjects' perceptions of MEs and the two BCSs were assessed as follows. First, the mean of the two matches to the top and bottom of each stimulus was expressed in C.I.E. coordinates. Then, the distance in C.I.E. space between these two loci was calculated; these distances approximate a combination of perceived saturations of the two matched colors. Finally, for each subject, the median of the distance values obtained in the four sessions was calculated for each of the three dependent variables. These medians were treated as individual scores in the analyses described below.

Figure 1 shows frequency distributions of saturation indices, that is, median distance values for ME, BCS1, and BCS2. The mean of all the subjects' MEs fell between the all-subject means of BCS1 and BCS2. The distributions of BCS1 and BCS2 did not overlap, but the range of MEs almost completely overlapped the combined ranges of BCS1 and BCS2; the standard deviation of the MEs was approximately twice that of the standard deviation of either BCS distribution.

For all three dependent variables, intraclass correlation coefficients were calculated for twin pairs. Twins' $R$ values for ME, BCS1, and BCS2 were, respectively, $.513, .524$, and .516 . They are all significant at $p<.02$ (using a one-tailed test).

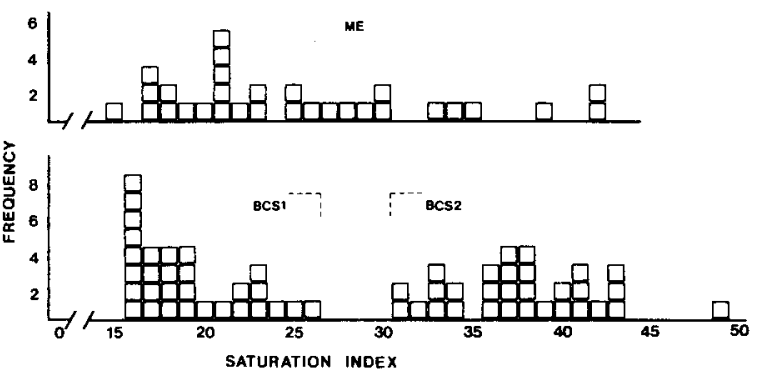

Figure 1. Frequency distribution of saturation indices for $\mathbf{M E}$, BCS1, and BCS2. Units on the abscissa are distances (in C.I.E. space $\times 10^{3}$ ) between loci for the two matched portions of each stimulus.

In order to assess within-subject similarities in the three dependent variables, product-moment correlations were performed between the variables in their three possible paired combinations. Results revealed the strongest association between the two physically chromatic stimuli $(r=.625)$, each of which had weaker associations with the ME (for ME/BCS1, $r=.241$; for $M E / B C S 2, r=.441$ )

Finally, in order to determine whether there were individual differences associated with subjects' age or sex, we subjected each dependent variable to a $2 \times 2$ ANOVA with subjects classified as pre- or postpubescent and male or female. None of the $F$ ratios were significant, but, where trends did exist, there was a tendency for females to give more saturated matches than males, and for prepubescent subjects to give more saturated matches than postpubescent subjects.

\section{DISCUSSION}

We compared matches to MEs with matches to physically chromatic stimuli similar in appearance to MEs. We found individual differences in matches to the externally generated hues to be smaller than individual differences in the internally generated colors of MEs. This finding is consistent with an assumption that mechanisms producing MEs are more complex than those producing sensations of physical hues, and are therefore subject to more sources of variability.

There were statistically significant correlations between the matches of twins to both MEs and the actual hues, and the coefficients were highly similar in magnitude. Intraclass Rs are ratios of the relative homogeneity of scores within twin pairs to the total variability among all the scores (see, e.g., Haggard, 1958), so the similarity of the Rs here does not indicate that the absolute magnitudes of intrapair differences were comparable for MEs and BCSs (and thus suggest that twins' MEs are as similar as their perceptions of the same physical stimulus). In fact, both intrapair variability and total variability were greater for MEs than for either BCS; however, the ratio of intertwin differences to intersubject differences was similar, regardless of the source of the perceived color. In other words, twins' MEs were about as similar as we would have 
predicted on the basis of extrapolation from the real-hue situation to one in which there are greater individual differences overall.

Taken as a whole, our results are consistent with other reports of individual differences in MEs. They also suggest that these differences may have a systematic biological component. We concur with Savoy (1984) that it will be important to determine whether factors such as general metabolic activity affect variability in MEs.

\section{REFERENCES}

Amure, B. (1978). Nicotine and the decay of the McCollough effect. Vision Research, 18, 1449-1451.

Bologna, N., MAY, J., \& KunEN, S. (1984). Age-related differences in the magnitude of pattern-contingent color aftereffects. Perception \& Psychophysics, 36, 349-352.

Cavonius, C., Hilz, R., \& Chapman, R. (1974). A possible basis for individual differences in magnitude-estimation behavior. British Journal of Psychology, 65, 85-91.

COREn,S., \& PORAC, C. (1979). Heritability in visual-geometric illusions: A family study. Perception, 8, 303-309.

Fraser, A., \& WilcoX, K. (1979). Perception of illusory movement. Nature, 281, 565-566.

HAGGARD, E. (1958). Intraclass correlation and the analysis of variance. New York: Dryden.

HARRIs, C. (1980). Insight or out of sight: Two examples of perceptual plasticity in the human adult. In C. S. Harris (Ed.), Visual coding and adaptability (pp. 95-149). Hillsdale, NJ: Erlbaum.

HaRris, J, (1983). Age, sex, and time of day effects on the duration of the movement aftereffect. British Journal of Psychology, 74, 233-238.

Kline, D., \& Nestor, S. (1977). Persistence of complementary afterimages as a function of adult age and exposure duration. Experimental Aging Research, 3, 191-201.

LUND, N., \& MACKAY, D. (1983). Sleep and the McCollough effect. Vision Research, 23, 903-906.

Matheny, A. (1971). Genetic determinants of the Ponzo illusion. Psychonomic Science, 24, 155-156.

MathenY, A. (1973). Hereditary components of response to the double trapezium illusion. Perceptual \& Motor Skills, 36, 511-513.

McCollough, C. (1965). Color adaptation of edge detectors in the human visual system. Science, 149, 1115-1116.
MCGUINNES, D., \& LEWIS, I. (1976). Sex differences in visual persistence: Experiments on the Ganzfeld and afterimages. Perception, 5, 295-301.

ReILLY, T. (1970). Some normative data for the spiral aftereffect. Perceptual \& Motor Skills, 31, 211-217.

Riggs, L., White, K., \& Eimas, P. (1974). Establishment and decay of orientation-contingent aftereffects of color. Perception \& Psychophysics, 16, 535-542.

SAvoY, R. (1984). "Extinction" of the McCollough effect does not transfer interocularly. Perception \& Psychophysics, 36, 571-576.

ShuTE, C. (1979). The McCollough effect: An indicator of central neurotransmitter activity. Cambridge: Cambridge University Press.

Skowbo, D., Garrity, S., \& Michaud, L. (1985). Does testing initiate decay of McCollough effects? Perception \& Psychophysics, 37, 377-381.

Skowbo, D., Timney, B., Gentry, T., \& Morant, R. (1975). McCollough effects: Experimental findings and theoretical accounts. Psychological Bulletin, 82, 497-510.

Stromeyer, C. (1978). Form-color aftereffects in human vision. In R. Held, H. Leibowitz, \& H-L. Teuber (Eds.), Handbook of sensory physiology: Vol. 8. Perception (pp. 97-142). New York: SpringerVerlag.

WHITE, K. (1976). Luminance as a parameter in establishment and testing of the McCollough effect. Vision Research, 16, 297-302.

WHITE, K. (1977). Summation of successively established orientationcontingent aftereffects. Perception \& Psychophysics, 22, 123-136.

Weintraub, D., Green, G., \& Herzog, T. (1973). Kinesthetic aftereffects day to day: Trends, task features, reliable individual differences. American Journal of Psychology, 86, 827-844.

\section{NOTES}

1. Of the five sets excluded from the study, one contained a previously undiagnosed dichromat, one contained an uncorrected hyperope, and three sets of relatively young twins (ages 7, 8, and 9) were not able to make fine enough color discriminations for our purposes.

2. Five such reports of color came from different subjects; three subjects reported them twice. Of the five, three described the opposite of the previous ME. Two of the three subjects who reported twice reported colors opposite to the previous ME on one of the two occasions. One subject had two reports of colors on the test slide which were consistent with previous MEs.

(Manuscript received June 7, 1985; revision accepted for publication August 9 , 1985.) 